\title{
Effect of Hard Cyclic Viscoplastic Deformation on Phases Chemical Composition and Micromechanical Properties Evolution in Single Crystal Ni-Based Superalloy
}

\author{
L. KOMMEL* \\ Tallinn University of Technology, Department of Materials Engineering, \\ Ehitajate tee 5, 19086 Tallinn, Estonia
}

\begin{abstract}
The phases chemical composition and micromechanical properties in single crystal of Ni-based superalloy with chemical composition of $12.1 \mathrm{Al}, 5.3 \mathrm{Cr}, 9.4 \mathrm{Co}, 0.8 \mathrm{Nb}, 0.9 \mathrm{Ta}, 0.7 \mathrm{Mo}, 2.5 \mathrm{~W}, 0.7 \mathrm{Re}$ and Ni-balance (in at.\%) were changed during hard cyclic viscoplastic deformation at room temperature. The method we used based on the Bauschinger effect. The changes in the dendritic microstructure and chemical composition were characterized by scanning electron microscopy and energy dispersive spectrometry. The phases micromechanical properties evolution were characterized by nanoindentation. The results show that the cumulative strain or strain energy density increase arouse the interdiffusion of atoms between the different phases and the phases equilibrium in SC was changed. It is established that the interdiffusion rate depends on elements atoms activation energy. The new $\gamma-\gamma^{\prime}$-eutectic pools were formed in the primary dendrites region (with fine $\gamma / \gamma^{\prime}$-phase) and as result the length of newly formed dendrites was decreased significantly. The maximal and plastic depth of nanoindentation were measured and the corresponding micromechanical properties of phases calculated.
\end{abstract}

DOI: 10.12693/APhysPolA.128.681

PACS: 81.05.Bx, 81.70.-q, 81.40.Jj, 87.15.Vv, 89.90.+n

\section{Introduction}

In the recent years, single crystal (SC) Ni-based superalloys have become attractive material for turbo-jet turbine blades and vanes manufacturing for advanced aviation application [1]. This high-strength refractory material experiences complex thermomechanical tensioncompression loads [2], fretting and metallurgical failure [3], oxidation and corrosion resistance [4], and vibration during exploitation in high-cycle fatigue (HCF) condition in high-temperature gas environment [5]. The testing of all these properties is complicated at one time and according to this the main test method of such SC Nibased superalloys is the creep testing under tension load with long exposure time at high temperatures [6]. During creep testing the raft microstructure can be formed [7]. The raft microstructure forming in $\mathrm{SC}$ Ni-based superalloy depends on the material chemical composition [8] and solidification parameters (withdrawal, solidification and cooling rates) at casting under high vacuum. By this the cooling rate influences both on the solidification behavior and the resultant structure as well chemical microheterogeneity of the casts [9]. Usually the diffusion of chemical elements and vacancies moving in such multicomponent systems are studied at high temperatures [10] according to the Fick first law. In the present work we studied interdiffusion processes in $\mathrm{SC}$ Ni-based superalloy at room temperature. We used hard cyclic

*e-mail: lembit.kommel@ttu.ee viscoplastic (HCV) deformation method for interdiffusion initiation in SC [11, 12]. The method we used based on the Bauschinger effect. The objective of the present investigation was to study the role that the deformationaided interdiffusion of chemical elements atoms among different phases plays in shifting the phase equilibrium, which was characterized, based on the evolving chemical composition and micromechanical properties of each phase. Such an investigation can provide realistic information concerning the shifts in the phase equilibria of SC Ni-based superalloy for aviation application.

\section{Experimental}

The commercially available SC Ni-based superalloy ZS-32vi (Russian standard) had the following chemical composition (in at.\%): $12.1 \% \mathrm{Al}, 5.3 \% \mathrm{Cr}, 9.4 \% \mathrm{Co}$, $0.8 \% \mathrm{Nb}, 0.9 \%$ Ta, $0.7 \%$ Mo, $2.5 \% \mathrm{~W}, 0.7 \%$ Re, and $\mathrm{Ni}$ balance. The casts were $16 \mathrm{~mm}$ in diameter and $160 \mathrm{~mm}$ in length. The withdrawing rate was $3.5 \mathrm{~mm} / \mathrm{min}$ [1]. From such casts there were cut off tension-compression test specimens with stepped cross-section areas (Fig. 1a). The cross-section areas were 200, 154, 77 and $38.5 \mathrm{~mm}^{2}$ (samples S1, S2, S3 and S4), respectively. The HCV deformation processing was conducted on Instron-8516 at tension-compression step-by-step increased strain amplitudes of $0 \%-0.05 \%, 0 \%-0.2 \%, 0 \%-0.5 \%$, and $0 \%-1 \%$ for 30 cycles, respectively. The strain amplitudes were controlled on sample $\mathrm{S} 4$ by extensometer with base length of $10 \mathrm{~mm}$. The microstructure and micromechanical properties of samples were studied only after straining at strain amplitude of $0 \%-1 \%$, respectively. 


\section{Results and discussion}

The corresponding dendrite microstructures of samples $\mathrm{S} 1, \mathrm{~S} 2, \mathrm{~S} 3$ and S4 are presented in Fig. 1b-e, respectively. The tension-compression maximal stress amplitude values were measured for sample S4 (Fig. 2).

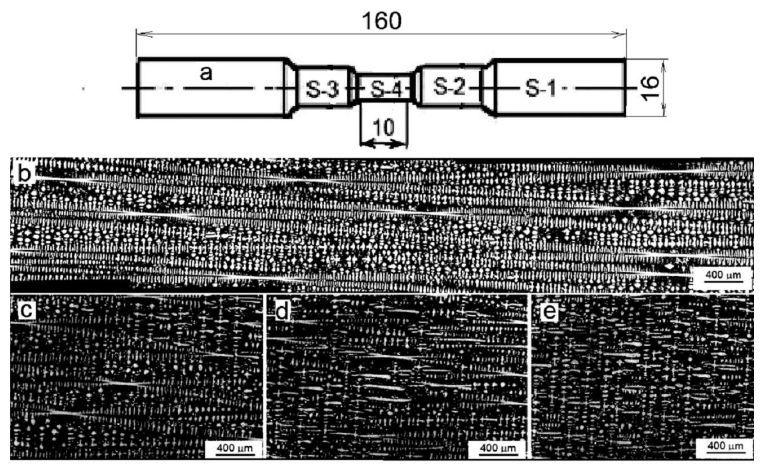

Fig. 1. Scheme of the tension-compression test specimen for $\mathrm{HCV}$ deformation (a), initial dendritic microstructure (b), and microstructures (c, d, and e) of samples S2, S3 and S4 after HCV deformation, respectively.

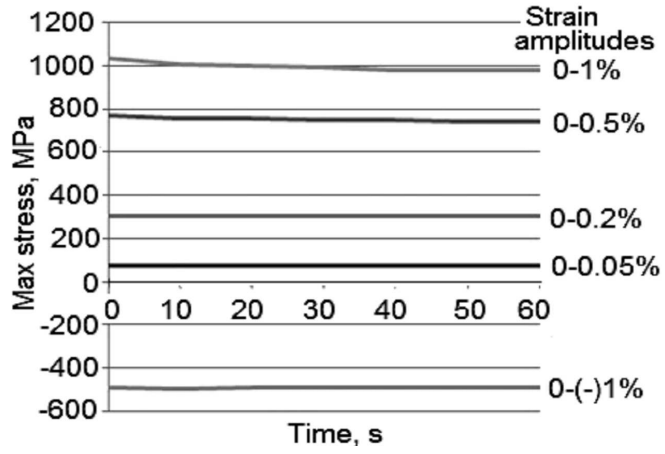

Fig. 2. Graph gives the maximal values of tensioncompression stress amplitudes (for corresponding strain amplitudes) on sample S4.

For the other samples the stress amplitudes were calculated proportionally to their cross-section. As is shown (in Fig. 1c-e) the dendrites microstructure was changed and the dendrites length was decreased from $\approx 5 \mathrm{~mm}$ down to $\approx 250 \mu \mathrm{m}$ in length. Such dendrites length was step-by-step decreased as the $\gamma-\gamma^{\prime}$-eutectic pools areas on the dendrites axis with fine $\gamma / \gamma^{\prime}$-phase microstructure were formed. The $\gamma-\gamma^{\prime}$-eutectic pools forming mechanism in the samples $\mathrm{S} 1$ and $\mathrm{S} 4$ is illustrated in Fig. 3a and b. The $\gamma-\gamma^{\prime}$-eutectic pools number and summarized area $\left(3 \mathrm{~mm}^{2}\right)$ in proportion of microstructure was step-by-step increased. These areas divide the dendrites by primary axis with $\gamma$ - $\gamma^{\prime}$-eutectic pools and as result the fine dendrites microstructure was formed (see Fig. 1e). Usually such microsegregation induced inhomogeneity in the $\gamma$ $\gamma^{\prime}$-eutectic pools takes place in a Ni-based SC superalloys at high temperatures [7]. There are two accessions to the diffusion investigation methods in $\mathrm{SC}$ Ni-based superalloy: the absolute reaction-rate theory and the dynamic theory of diffusion [13]. These theories demonstrate that the diffusive motion of atoms primary depends on the strain amplitudes of oriented vibration and the neighbourhood with different elements atoms. It is shown also that the diffusion activation energy varies with the size, atomic weight, and charge of the diffusion description.

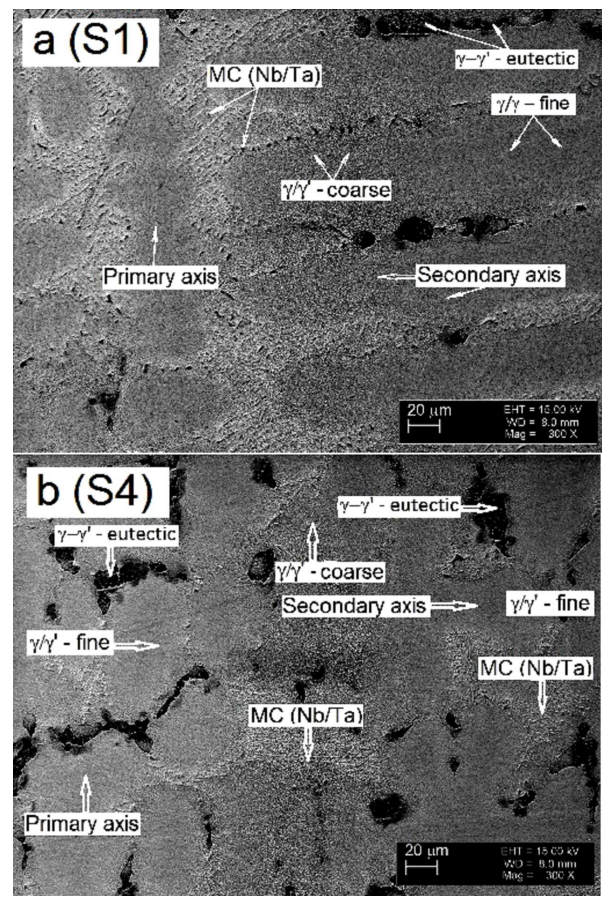

Fig. 3. The SEM pictures show the $\gamma-\gamma^{\prime}$-eutectic pools forming mechanism in samples $\mathrm{S} 1$ and $\mathrm{S} 4$, respectively.

This activation or cumulative SED varies with the size, atomic weight, and change of the diffusion species. Therefore, it is different for different elements as well different phases. In present study this activation energy was provided by $\mathrm{HCV}$ deformation at room temperature and was expected to vary with the cumulative strain. A large number of energy-dispersive spectrometry investigations demonstrated that $\mathrm{Al}$ diffused along the dendrite axis, whereas Re and W diffuse from the coarse $\gamma / \gamma^{\prime}$-phase into the fine $\gamma / \gamma^{\prime}$-phase and partly into the $\gamma-\gamma^{\prime}$ - eutectic pools. Therefore, the $\mathrm{Al}$ diffuse to the dendrite axis from the $\gamma-\gamma^{\prime}$-eutectic pools. The $\mathrm{Cr}$, Mo and Co diffused to the $\gamma-\gamma^{\prime}$-eutectic pools. For the MC, Ta and Nb diffused to the fine $\gamma / \gamma^{\prime}$-phase. Such elements diffusion directions are shown by arrows in Fig. $3 a$ and $b$ and in Fig. 4 by elements diffusion directions, respectively.

As result, the interdiffusion homogenized the $\mathrm{SC} \mathrm{Ni}$ based superalloy dendritic microstructure. Such diffusion of elements and vacancies in multicomponent systems are described in [10]. The micromechanical properties by nanoindentation under load of $15 \mathrm{mN}$ (Fig. 5) were tested in coarse $\gamma / \gamma^{\prime}$ phase (a), fine $\gamma / \gamma^{\prime}$ phase (b), $\gamma-\gamma^{\prime}$-eutectic phase (c) and $\mathrm{Nb} /$ Ta-rich MC phase (d). The micromechanical properties were calculated automatically. The chemical conditions near these points were analyzed three times for all phases. 


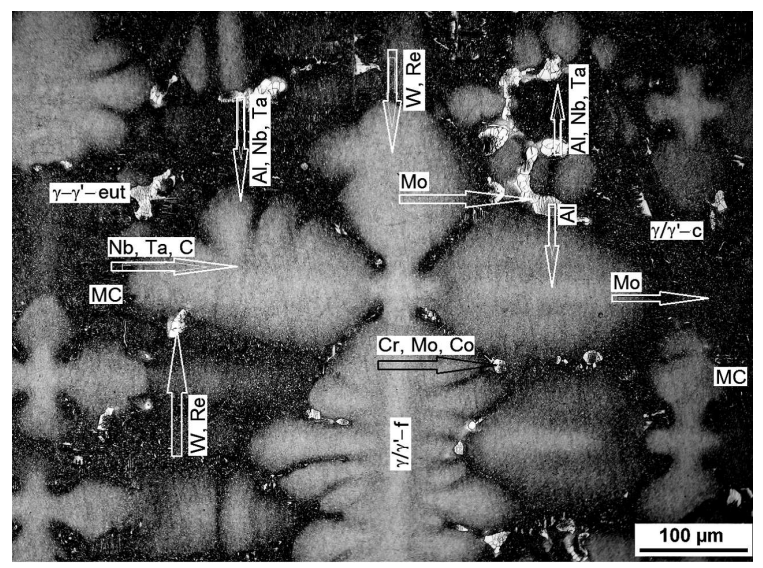

Fig. 4. Mine directions of elements atoms motion at interdiffusion in the cross-section of sample.

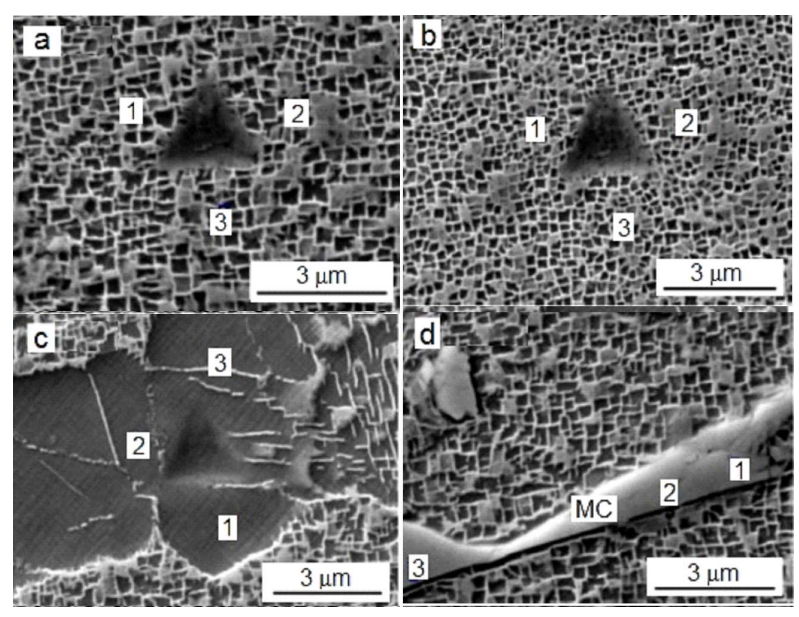

Fig. 5. The SEM pictures show the nanoindentation test indents in coarse $\gamma / \gamma^{\prime}$ phase (a), fine $\gamma / \gamma^{\prime}$ phase (b), $\gamma$ - $\gamma^{\prime}$ eutectic phase (c) and $\mathrm{Nb} /$ Ta-rich MC phase (d) as well chemical analyze points.

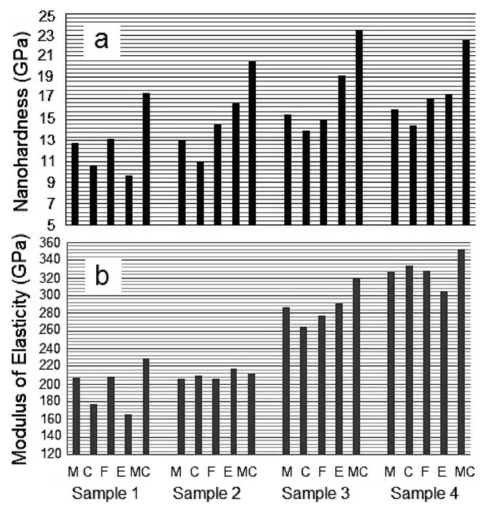

Fig. 6. Diagrams give the nanohardness (a) and modulus of elasticity (b) of samples and phases. Definitions: $\mathrm{M}$ - mean values of nanohardness and modulus of elasticity, C - coarse $\gamma / \gamma^{\prime}$-phase, F - fine $\gamma / \gamma^{\prime}$-phase, E $-\gamma-\gamma^{\prime}$-eutectic phase and MC - metal carbide phase, respectively.
Some results of micromechanical properties are presented in graphs (Fig. 6). The test results of nanoindentation show that by cumulative strain or strain energy density increase causes the increase of the nanohardness (Fig. 6a) and modulus of elasticity (Fig. 6b). By this, increase of the nanohardness causes the contact compliance parameter, elastic recovery parameter and elastic work of indentation to decrease (not shown in this study). The plastic work of indentation does not decrease so sharply.

\section{Conclusions}

The results of this investigation strongly indicate that these changes in the micromechanical properties of the phases are related to the change in the chemical elements concentrations of the phases during $\mathrm{HCV}$ deformation at interdiffusion. The effect of $\mathrm{HCV}$ deformation aided interdiffusion influence on the phase equilibria of SC sample of a Ni-based superalloy at room temperature. The primary dendrites in the (001) direction were separated by $\gamma-\gamma^{\prime}$ eutectic pools and the length of the newly formed dendrites was decreased, the microstructure was finer and properties of SC Ni-based superalloy improved as result.

\section{Acknowledgments}

The support from the Estonian Ministry of Education and Research by Project IUT 19-29 and EU 7 FP Project ERA.Net RUS STProjects-219 is greatly appreciated.

\section{References}

[1] R.C. Reed, The Superalloys, Fundamentals and Applications, Cambridge University Press, New York 2006.

[2] J.X. Zhang, H. Harada, Y. Ro, Y. Koizumi, T. Kobayashi, Acta Mater. 56, 2975 (2008).

[3] Z. Huda, Mater. Des. 30, 3121 (2009).

[4] A. Akhtar, S. Hegde, R.C. Reed, JOM - J. Minerals Metals Mater. Soc. 58, 37 (2006).

[5] Y. Liu, J.J. Yu, Y. Xu, X.F. Sun, H.R. Guan, Z.Q. Hu, Mater. Sci. Eng. A 454-455, 357 (2007).

[6] F.H. Latief, K. Kakehi, H. Murakami, Scr. Mater 68, 126 (2013).

[7] A. Epishin, T. Link, U. Brückner, Acta Mater. 49, 4017 (2001).

[8] J. Svoboda, P. Lukáš, Acta Mater. 48, 2519 (2000).

[9] J. Dobrovská, S. Dočekalová, V. Dobrovská, K. Stránský, Solid State Phenom. 138, 201 (2008).

[10] F.D. Fischer, J. Svoboda, Progr. Mater. Sci. 60, 338 (2014)

[11] L. Kommel, Mater. Sci. (Medžiagotyra) 15, 123 (2009).

[12] L. Kommel, B. Straumal, Def. Diff. Forum 297301, 1340 (2010).

[13] M. Huang, L. Zhao, J. Tong, Int. J. Plasticity 28 , $141(2012)$. 